\title{
Electron microscopic studies of thermomechanically aged 2218 aluminium alloy
}

\author{
MUKESH KUMAR, S SINGH and D B GOEL \\ Department of Metallurgical Engineering, University of Roorkee, Roorkee 247667 , India \\ MS received 16 January 1988
}

\begin{abstract}
The effect of thermomechanical ageing (TMA) treatment on the microstructure and mechanical properties of $2218 \mathrm{Al}$ alloy has been studied. This was followed by hardness measurements and transmission electron metallography (TEM). The $2218 \mathrm{Al}$ alloy was given various thermomechanical ageing treatments including partial peak ageing, warm rolling and further ageing to peak hardness level. Without thermomechanical treatment the peak hardness value was $130 \mathrm{VHN}$. With thermomechanical treatment there was an overall improvement in hardness. This is attributed to the combined effect of dislocation precipitate networks and the fineness of $\theta^{\prime}$ particles.
\end{abstract}

Keywords. Thermomechanical ageing; 2218 Al alloy; transmission electron metallography; plastic deformation; precipitation; zone formation; dislocation; microstructure.

\section{Introduction}

Aluminium and its alloys are popular in various applications in engineering design chiefly on account of their light weight, high specific tenacity, resistance to corrosion and relatively low cost and ability to undergo precipitation hardening treatment. The special characteristics of $2218 \mathrm{Al}$ alloy is its ability to retain a good strength at relatively high temperature. This property is desirable in aeroengine pistons, motor pistons, cylinder heads and automobile parts. This alloy finds extensive applications where high strength, relatively good formability and high hardness are required and hence is widely used in industries in the form of heavy duty forgings, power shovels, boilers, aircraft fittings, truck frames and army armament items etc.

In the present investigation an attempt has been made to modify or control the microstructure of $2218 \mathrm{Al}$ alloy by appropriate treatment to eliminate or minimize the density of inclusions to improve the overall mechanical properties. The effect of various parameters on mechanical properties and microstructural changes has been investigated on $2218 \mathrm{Al}$ alloy of commercial purity. The main parameters investigated are the degree of preaging and the amount of deformation prior to final ageing with the microstructural feature of precipitate dislocation network.

Several workers (Lipsitt and Sargent 1970; Guyot and Winten Berger 1974) have reported developing such structures in Al alloy which can withstand high temperature effect without much loss in hardness and strength. Sommer et al (1972) strongly recommended warm work as a necessary processing step during TMA treatment in achieving a desirable balance of properties. Earlier studies on the effect of TMA treatment on different properties of 6000 and 7000 series Al alloy (Rack and Krenzer 1977; Santner 1978; Starke and Sanders 1978) showed a positive effect of TMA treatment on the mechanical properties of these alloys.

\section{Experimental}

The $2218 \mathrm{Al}$ alloy was prepared using $99 \cdot 7 \%$ pure aluminium and $99.9 \%$ pure $\mathrm{Cu}, \mathrm{Ni}$ 
and $\mathrm{Mg}$ and melted using a muffle furnace. Hexachloroethane was used for degassing and analysis by atomic absorption spectroscopy. The nominal and actual chemical compositions are given in table 1 . The cast alloy was homogenized at $510^{\circ} \mathrm{C}$ for $4 \mathrm{~h}$ and hot-rolled at $425^{\circ} \mathrm{C}$ into cross-sections, from which the sample of $20 \times 20 \times 25 \mathrm{~mm}$ size was cut for hardness measurements.

Various properties were measured in the following conditions: (i) As quenched [solution treatment at $510^{\circ} \mathrm{C}$, followed by water quenching], (ii) peak aged [artificial ageing at $160^{\circ} \mathrm{C}$ to peak hardness], (iii) TMA Ia [25\% preageing, 10\% warm rolling and further ageing to peak hardness value], (iv) TMA Ib [25\% preageing, 20\% warm rolling and further ageing to peak hardness value], (v) TMA Ic [25\% preageing, 30\%. warm rolling and further ageing to peak hardness value], (vi) TMA IIa [ $50 \%$ preageing, 10\% warm rolling and further ageing to peak hardness value], (vii) TMA IIb [50\% preageing, 20\% warm rolling and further ageing to peak hardness value], (viii) TMA IIc [ $50 \%$ preageing, 30\% warm rolling and further ageing to peak hardness value], (ix) TMA IIIa [peak aged, 10\% warm rolling and subsequently aged], (x) TMA IIIb [peak aged, 20\% warm rolling and subsequently aged] and (xi) TMA IIIc [peak aged, $30 \%$ warm rolling and subsequently aged]. In all the above mentioned treatments, warm rolling and ageing were carried out at $160^{\circ} \mathrm{C}$. The ageing behaviour was followed by hardness measurements (figure 1). The effect of TMA treatment on microstructural features like size, shape and distribution of precipitates and dislocation particle tangles was studied using a transmission electron microscope (Phillips EM 400) at high magnification on thin foil samples prepared by the window technique. Electrothinning of the foil samples was carried out at $11 \mathrm{~V}$ and $70^{\circ} \mathrm{C}$. The following volumetric composition of the electrolyte was used:

$$
\begin{array}{ll}
\mathrm{H}_{3} \mathrm{PO}_{4}-817 \text { c.c. } & \mathrm{H}_{2} \mathrm{O}-40 \text { c.c. } \\
\mathrm{H}_{2} \mathrm{SO}_{4}-134 \text { c.c. } & \mathrm{Cr}_{2} \mathrm{O}_{3}-156 \mathrm{~g}
\end{array}
$$

\section{Results and discussion}

Results of the hardness measurements plotted against ageing time on log scale are shown in figures 1 and 2 . With ageing the hardness of undeformed specimen rises continuously from an as-quenched value of $65 \cdot 10$ VHN to a peak value of $130 \cdot 70$ VHN after $6 \mathrm{~h}$ at $160^{\circ} \mathrm{C}$. On further ageing there is a gradual fall in hardness due to overageing phenomenon. The hardness value after 25,50 and $100 \%$ preageing and 10,20 and $30 \%$ deformations are also plotted in figures 1 and 2 . The hardness rises to higher values after deformation in all preageing conditions. Among all the TMA

Table 1. Nominal and actual composition of $2218 \mathrm{Al}$ alloy.

\begin{tabular}{lcc}
\hline Element & $\begin{array}{c}\text { Nominal range } \\
(\text { Wt. \%) }\end{array}$ & $\begin{array}{c}\text { Actual composition } \\
\text { (Wt. \%) }\end{array}$ \\
\hline $\mathrm{Cu}$ & $3 \cdot 50-4 \cdot 50$ & $3 \cdot 89$ \\
$\mathrm{Ni}$ & $1 \cdot 70-2 \cdot 30$ & $2 \cdot 00$ \\
$\mathrm{Mg}$ & $1 \cdot 20-1 \cdot 80$ & $1 \cdot 70$ \\
$\mathrm{Al}$ & Balance & Balance \\
$\mathrm{Fe}$ (As impurity) & $0 \cdot 80$ max & $0 \cdot 70$ \\
\hline
\end{tabular}




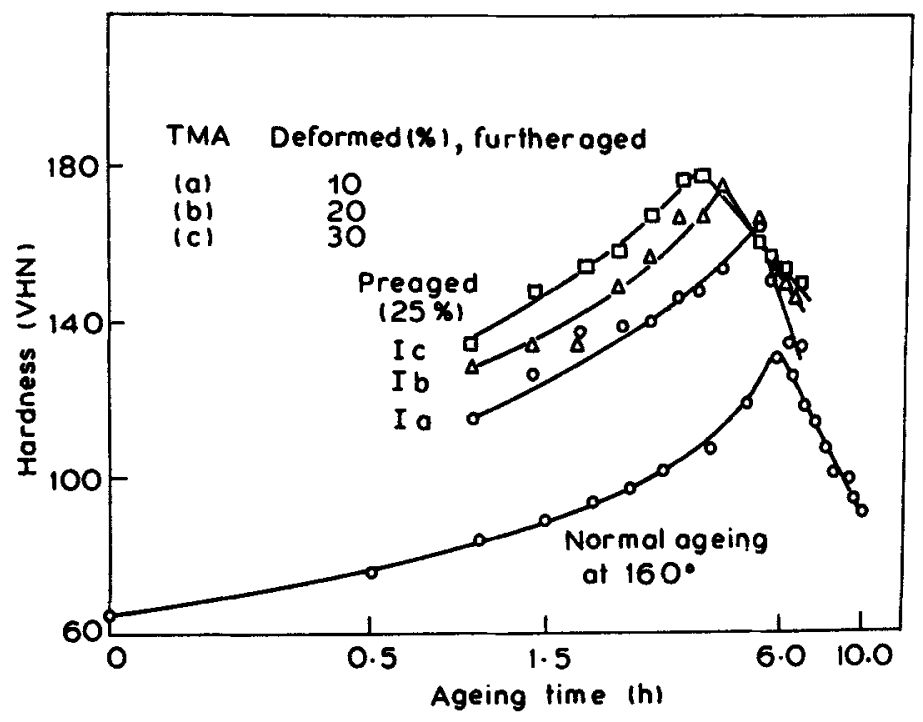

Figure 1. Ageing curves for thermomechanically processed $2218 \mathrm{Al}$ alloy at $160^{\circ} \mathrm{C}$ for 25 pct preaged samples.

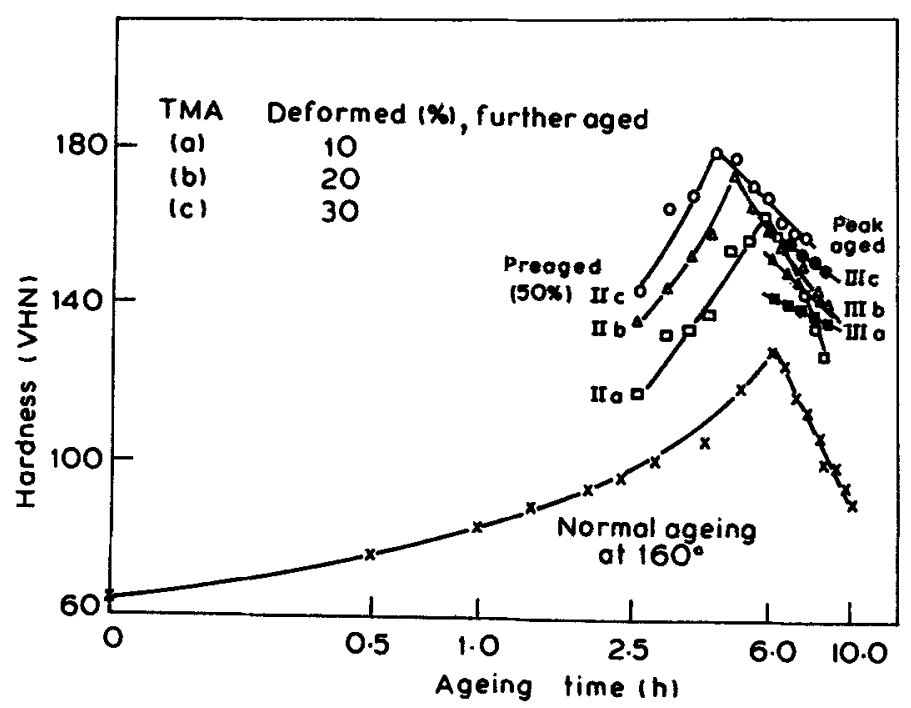

Figure 2. Ageing curves for thermomechanically processed $2218 \mathrm{Al}$ alloy at $160^{\circ} \mathrm{C}$ for 50 pct and 100 pct preaged samples.

treatments, TMA II treatment gives maximum effect on increase in peak hardness. It can be clearly seen that the increase in deformation value from $10 \%$ to $20 \%$ increases the hardness value by 19 VHN after TMA II treatment, as against $10 \mathrm{VHN}$ increase for TMA I and 11 VHN increase for TMA III treatment only. Similar effect can also be seen for other deformation values. The deformation shortens the ageing period needed for obtaining the peaks. The $30 \%$ deformation is more effective in shifting the peak to lower ageing time compared to 10 and $20 \%$ deformations (figures 1 and 2). 
The shorter time and increase in peak hardness values is due to the combined effect of precipitation and dislocation substructure. The dislocations may act as potential sites for precipitation of second phase from their parent matrix. Since dislocations are generated as a result of plastic deformation. nucleation sites are increased and the precipitation process is accelerated. Therefore precipitation of nonequilibrium phase becomes easier. As non-equilibrium precipitates grow, coherency gets lost due to overageing and there is a drop in hardness.

Under normal peak-aged condition the microstructure is predominantly characterized by the presence of $\theta^{\prime}$ precipitates of $2000 \AA$ size. TMA treatment enhances nucleation sites in the formation of $\theta^{\prime}$, which leads to the development of finest $\theta^{\prime}$ precipitates of size $950 \AA$ in TMA II-treated samples. In addition to ageing kinetics, different magnitudes of dislocation-precipitate tangles have also been observed after various TMA treatments.

The duration of final ageing operation in TMA III $\mathrm{C}$ is zero $\mathrm{h}$ as against $1.50 \mathrm{~h}$ in TMA IIC and $3.50 \mathrm{~h}$ in TMA Ic and hence the extent of annihilation and rearrangement of dislocations in TMA IIIC is much smaller than in TMA IIC and in TMA IC. In addition, the microstructures at the beginning of the final ageing step consist of

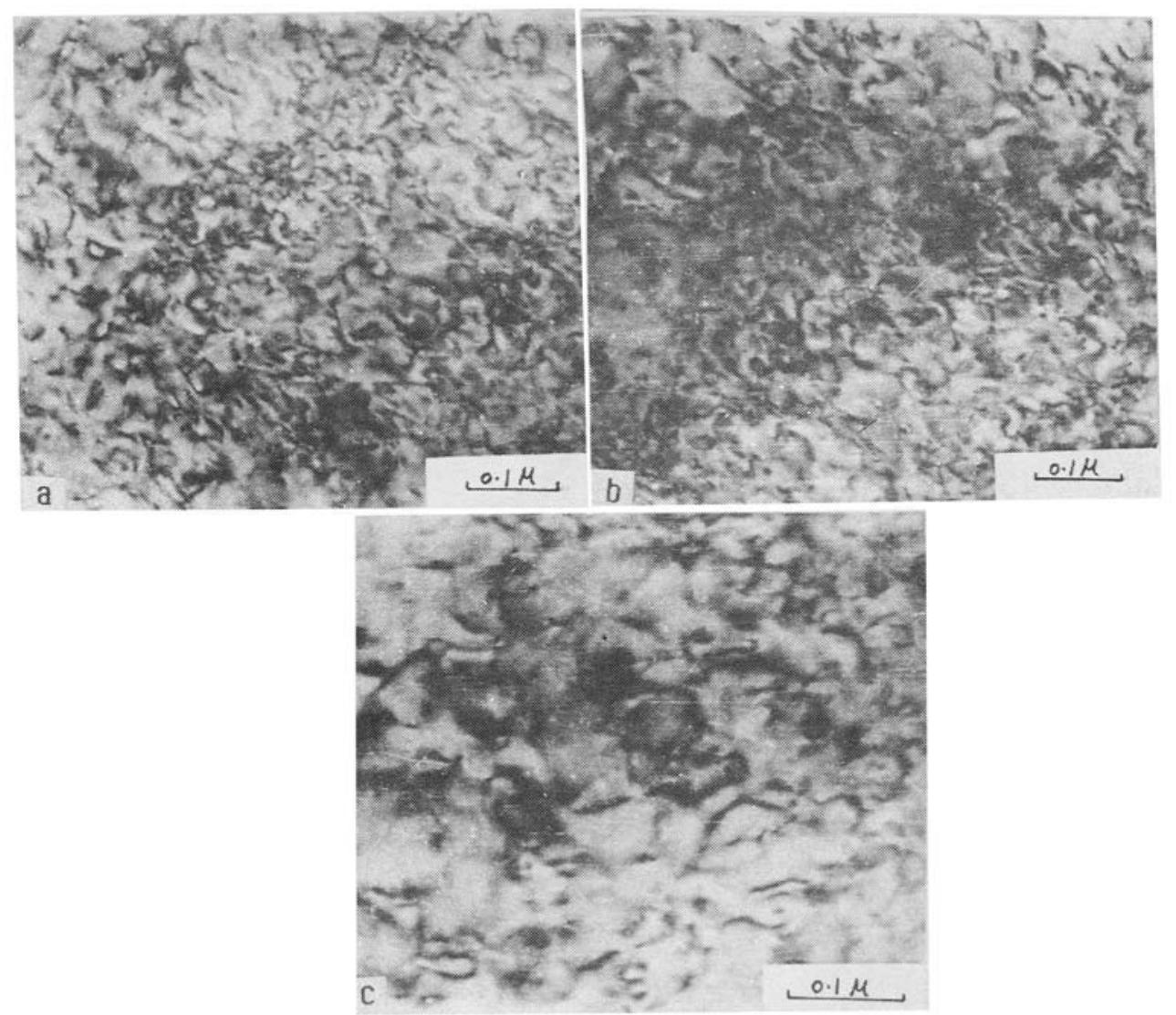

Figure 3. Transmission electron micrographs of TMA treated specimens showing dislocation-precipitate tangles. a. IIIc. b. IIc. c. Ic. 


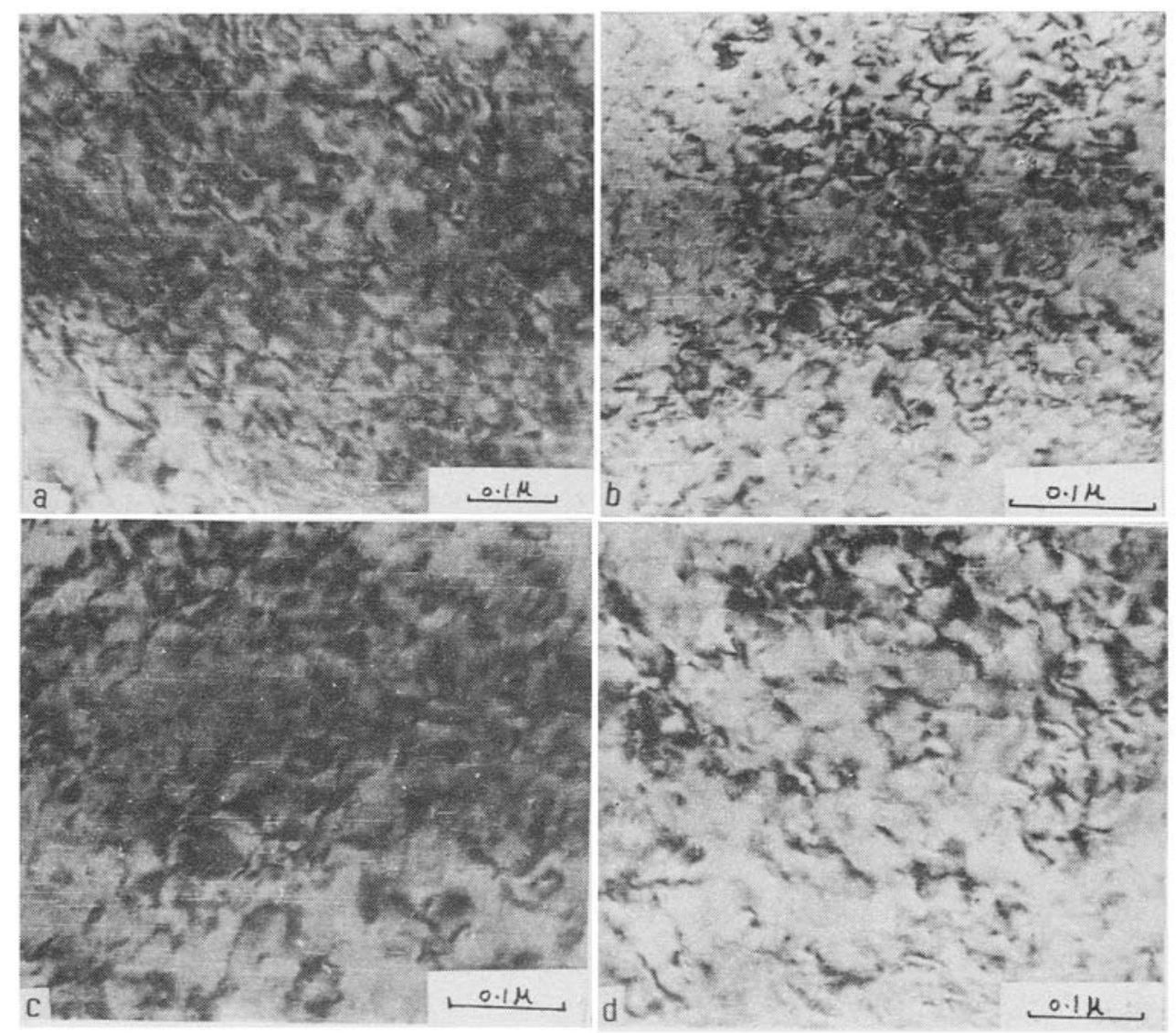

Figure 4. Transmission electron micrographs of TMA treated specimens showing dislocation-precipitate tangles. a. IIIb. b. IIb. c. IIIa. d. IIa.

higher density of $\theta^{\prime}$ particles in TMA IIC than in TMA IC, which also inhibits annihilation and rearrangement of dislocations in TMA IIC treatment. Another factor which helps in annihilation of dislocations, preferentially in TMA IC is the release of dislocation energy due to nucleation of $\theta^{\prime}$ at the dislocations. Thus the thickest dislocation particle tangles are observed after TMA IIIC treatment, whereas the minimum after TMA IC treatment and intermediate magnitude has been observed after TMA IIC treatment (figure 3). Similarly thick dislocation precipitate tangles were observed after TMA IIIb and IIIa as compared to TMA IIb and IIa and TMA Ib and Ia treatment (figure 4). The combined effect of fineness of $\theta^{\prime}$ precipitates and density of dislocation $(\rho)$ lead to the highest hardness after TMA IIc treatment.

\section{Conclusions}

(i) The thermomechanical ageing treatments enhance the peak hardness values and shorten the time to reach the peak hardness. Maximum improvement in hardness is observed after TMA IIc treatment, which involves $50 \%$ preageing, followed by $30 \%$ warm rolling and further ageing to peak hardness value at $160^{\circ} \mathrm{C}$. 
(ii) The improvement in hardness after thermomechanical treatments is attributed to the combined effect of dislocation precipitate tangles as well as the density and fineness of $\theta^{\prime}$ precipitates.

(iii) All the TMA treatments tend to accelerate the formation of $\theta^{\prime}$. These treatments also increase the fineness of $\theta^{\prime}$ precipitates.

\section{References}

Guyot P and Winten Berger M 1974 J. Mater. Sci. 9619

Lipsitt H A and Sargent C M 1970 Proc. Second Int. Conference on the strength of metals and alloys (ASM) 937, Pacific Grove, California, Aug. 30-Sept. 4, 1970. ASM, Metals Park, Ohio

Pattanaik S, Srinivasan V and Bhatia M L 1972 Scr. Met. 6191

Rack H J and Krenzer R W 1977 Metall Trans. A8 335

Santner S Joseph 1978 Metall. Trans. A9 769

Sommer A W, Paton N E and Folgner D G 1972 Feb. Airfore materials Laboratory technical report No. AFML-TR-72-5

Starke E A Jr and Sanders R E Jr 1978 Metall. Trans. A9 1087 